\title{
Sistem Billboard Digital Cerdas Menggunakan Metode Jaringan Syaraf Tiruan dengan Orientasi Pendeteksi Jarak dan Usia
}

\author{
Teguh Adiaksa Wicaksono \\ Teknik Elektro \\ Universitas Merdeka Malang \\ Malang, Indonesia \\ teguh.adiaksa13@gmail.com
}

\author{
Nachrowie \\ Teknik Elektro \\ Universitas Merdeka Malang \\ Malang, Indonesia \\ nachrowie@unmer.ac.id
}

\author{
*Irfan Mujahidin \\ Teknik Elektro \\ Universitas Merdeka Malang \\ Malang, Indonesia \\ *Irfan.mujahidin@unmer.ac.id
}

\begin{abstract}
The development of technology in an increasingly sophisticated industrial era is evidenced by the presence of modern equipment produced to speed up and simplify a job. In Advertising currently has no filtering about the age of its readers. Based on this background this study built a system for billboard display (advertising) based on age. For the method used using the method of artificial neural networks. For testing the tool uses distance parameters based on objects that are indexed with two categories namely adults and children. For the test results using 4 objects of people with a distance of 1 meter to 5 meters per object obtained the results detected each adult and small children distanced 1 meter to 3 meters in a distance of 4 meters to 5 meters undetected with an accuracy of $80 \%$.
\end{abstract}

Keywords - Billboard, Artificial Neural Network, Detector

\section{PENDAhUluan}

Pesatnya perkembangan teknologi di era industri 4.0 dibuktikan dengan adanya peralatan peralatan modern yang dihasilkan untuk mempercepat dan mempermudah siatu pekerjaan[1][2]. Contoh dalam kasus dftar pencarian orang contoh dalam kasus daftar pencarian orang (DPO), dibuat sebuah sistem yang bisa mendeteksi atau mengenali wajah objek yang dicari, metode yang digunakan yaitu jaringan syaraf tiruan[3][4]. Metode jaringan syaraf tiruan yakni salah satu representasi buatan pada otak manusia yang terus - menerus mencoba mensimulasikan proses pembelajaran pada otak manusia tersebut.

Pemanfaatan camera pada iklan bisa digunakan sebagai filter, cara yang digunakan adalah dengan bantuan image prosesing. Filter dengan bantuan kamera ini adalah mengelompokkan setiap wajah yang terdeteksi berdasarkan usia[5][6][7].

\section{TEORI DASAR}

Jaringan syaraf tiruan merupakan salah satu representasi buatan dari otak manusia yang selalu mencoba untuk mensimulasikan proses pembelajaran pada otak manusia tersebut Istilah buatan disini digunakan karena jaringan syaraf ini diimplementasikan dengan menggunakan program komputer yang mampu menyelesaikan sejumlah proses proses pembelajaran[8][9][10]. perhitungan selama

\section{A. Komponen Jaringan Syaraf}

Ada beberapa model jaringan saraf, tetapi demikian, hampir semuanya memiliki komponen-komponen yang sama. Seperti halnya otak manusia, jaringan saraf juga terdiri dari beberapa neuron, dan ada hubungan antara neuron-neuron tersebut[11]. Neuron-neuron tersebut akan mentransformasikan informasi yang diterima melalui

sambungan keluarnya menuju neuron-neuron yang lain. Pada jaringan saraf, hubungan ini dikenal dengan nama bobot informasi tersebut disimpan pada suatu nilai tertentu pada bobot tersebut[12][13].

Neuron buatan sama persis dengan sel biologis. Neuron-neuron akan bekerja dengan cara yang sama pula dengan neuron-neuron biologis informasi (disebut dengan: input) akan dikirim ke neuron dengan bobot kedatangan tertentu[14][15]. Input ini akan diproses oleh suatu fungsi perambatan yang akan menjumlahkan nilainilai semua bobot yang datang. Hasil penjumlahan ini kemudian akan dibandingkan dengan suatu nilai ambang (threshold) tertentu melalui fungsi aktivasi setiap neuron[16][17]. Apabila input tersebut melewati suatu nilai ambang tertentu, maka neuron tersebut akan diaktifkan, tapi kalau tidak, maka neuron tersebut tidak akan diaktifkan. Apabila neuron tersebut diaktifkan, maka neuron tersebut akan mengirimkan output melalui bobotbobot outputnya kesemua neuron yang berhubungan dengan nya, demikian seterusnya[18][19].

Pada jaringan saraf, neuron-neuron akan dikumpulkan dalam lapisan-lapisan (layer) yang disebut dengan lapisan neuron (neuron 


\section{Sistem Billboard Digital Cerdas Menggunakan Metode Jaringan Syaraf Tiruan dengan Orientasi Pendeteksi Jarak dan Usia}

layers). Umumnya neuron-neuron pada satu lapisan akan dihubungkan dengan lapisan-lapisan sebelum dan sesudahnya (kecuali lapisan input dan lapisan ouput). Informasi yang diberikan pada jaringan saraf akan dirambatkan lapisan ke lapisan, mulai dari lapisan input sampai ke lapisan output melalui lapisan yang lainnya, yang sering dikenal dengan nama lapisan tersembunyi (hidden layer)[20][21]. Tergantung pada algoritma pembelajarannya bisa jadi, informasi tersebut akan dirambatkan secara mundur pada jaringan

Bukanlah struktur umum jaringan saraf. Beberapa jaringan saraf ada juga yang tidak memiliki lapisan tersembunyi, dan ada juga jaringan saraf dimana neuron-neuronnya disusun dalam bentuk matriks[22][23].

\section{B. Metode Haar Cascade Classifier}

Algoritma haar feature. Haar feature itu sendiri yaitu fitur yang berdasarkan pada gelombang wavelet haar. Wavelet haar ialah gelombang tunggal Hang berbentuk bujur sangkar dengan satu interval rendah dan satu interval tinggi untuk objek dua dimensi yang terdiri dari terang dan gelap, berikutnya kombinasi yang berbentuk kotak yang akan digunakan pada saat pendeteksian objek visual untuk lebih baik. Setiap metode haar like feature memiliki semua kotak putih dan kotak hitam[24][25]. Fitur pada metode haar ditentukan dengan mengurangkan rata-rata pixel di daerah terang dan rata-rata pixel di daerah gelap. Jika nilai threshold atau nilai ambang terdapat nilai perbedaannya, maka bisa dikatakan kalau fitur tersebut ada. Nilai dari metode haar like feature merupakan perubahan antara jumlah pixel gray level pada daerah kotak putih dan daerah kotak hitam. perhitungan secara cepat pada metode haar like feature menggunakan "integral image" agar hasilnya lebih cepat[26][27].

Integral Image digunakan sebagai menentukan sampel ada atau tidaknya di dalam ratusan fitur dalam sebuah gambar dengan cepat dan dengan skala berbeda secara efisien.

Integral Image digunakan sebagai menentukan sampel ada atau tidaknya di dalam ratusan fitur dalam sebuah gambar dengan cepat dan dengan skala berbeda secara efisien[28].

Seperti pada gambar 4 setelah mengintegrasikan, nilai pada pixel sumbu ( $\mathrm{x}, \mathrm{y})$ berisi jumlah semua pixel di dalam daerah segiempat mulai dari kiri atas sampai pada lokasi sumbu (x, y) atau daerah yang diarsir. Untuk memperoleh nilai pixel pada daerah yang diarsir (area segiempat) ini hanya bisa dilakukan dengan membagi nilai sumbu ( $\mathrm{x}, \mathrm{y})$ pada area yang berbentuk segiempat[29][30].

$$
i i(x, y)=\sum_{x^{\prime} \leq x, y^{\prime} \leq y} i\left(x^{\prime}, y^{\prime}\right)
$$

Dimana ii sumbu $(x, y)$ merupakan integral image dan $i$ sumbu $\left(x^{\prime}, y^{\prime}\right)$ adalah original image. Sebuah metode classifier dalam sebuah struktur tingkatan yang kompleks pada metode ini dapat kecepatan pendeteksian objek dapat ditingkatkan hanya dengan memfokuskan pada daerah citra saja[31][32].

Meningkatkan kecepatan pendeteksian dilakukan menggunakan algoritma adaboost. Algoritma Adaboost digunakan untuk meningkatkan kinerja klasifikasi dengan pembelajaran sederhana untuk menggabungkan

banyak classifier lemah menjadi satu classifier kuat, classifier lemah merupakan suatu jawaban benar dengan tingkat kebenaran yang kurang akurat sebuah classifier lemah dinyatakan:

$$
h_{t}(x)= \begin{cases}1, \text { jika } & p_{t} f_{t}(x)<p_{t} \theta_{t}(x) \\ 0 & \text { lainnya }\end{cases}
$$

$h_{t}(\mathrm{x})$ adalah klasifikasi lemah, $p_{t}$ adalah parity ke t, $\theta_{t}$ merupakan threshold ke t dan x yaitu dimensi sub image. Selanjutnya nilai fitur baru yang telah diklasifikasikan digabungkan dengan banyak fitur dengan cascade classifier.

Cascade classifier merupakan sebuah metode untuk dikombinasikan dengan classifier yang kompleks yang dapat meningkatkan kecepatan pendeteksian objek.



Gambar 1 Cascade Classifer Face

Gambar 1 menunjukkan logika face detector melakukan Analisa pada sebuah objek berupa gambar. Jika sebuah objek gambar (dari file / video), face detector mendeteksi di setiap lokasi objek dan mengklasifikasi sebagai sebuah objek wajah atau bukan. Klasifikasi di ibaratkan sebuah skala tetap untuk wajah, misal $50 \times 50$ pixel. Jika wajah pada objek gambar atau video lebih kecil atau lebih besar dari pixel tersebut, metode classifier ini terus menerus berjalan, untuk mencari objek wajah pada gambar atau video tersebut[33][34].

\section{Arsitektur Jaringan}

Seperti telah dijelaskan sebelumnya bahwa neuron-neuron dikelompokan dalam lapisanlapisan. Umumnya, neuron-neuron yang terletak pada lapisan yang sama akan memiliki keadan yang sama faktor terpenting dalam menentukan kelakuan suatu neuron merupakan fungsi aktivasi dan pola bobotnya. Pada setiap lapisan yang sama neuronneuron akan memiliki fungsi aktifasi yang sama. Apabila neuron-neuron dalam suatu lapisan 


\section{Sistem Billboard Digital Cerdas Menggunakan Metode Jaringan Syaraf Tiruan dengan Orientasi Pendeteksi Jarak dan Usia}

(misalkan lapisan tersembunyi) akan dihubungkan dengan neuron-

neuron pada lapisan yang lain (misalkan lapisan output).

\section{Beberapa Kesalahan Umum}

Face detection merupakan sebuah teknologi dari hasil proses komputer yang digunakan untuk mengidentifikasi wajah seseorang melalui citra digital yang tertangkap oleh kamera. Sistem ini merupakan sebuah tugas utama dari sistem penglihatan manusia yang dengan mudah dilakukan setiap hari, namun kemudahan ini masih sulit untuk sebuah alat yang ingin menyamai seperti kemudahan pada manusia. Pendeteksi wajah merupakan satu bentuk dari teknik pengolahan citra dengan mencocokkan bentuk wajah, tekstur wajah maupun banyak hal yang bisa diidentifikasi. Sistem pengenal wajah harus bisa otomatis mendeteksi wajah dalam gambar ini melibatkan ekstrak fitur dan

kemudian mengenalinya, terlepas dari pencahayaa n ekspresi, pencahayaan, penuaan, transformasi (translate, rotate and scale image) dan pose, yang merupakan tugas yang sulit.

\section{METODOLOGI PENELITIAN}

Setelah perancangan dan pembuatan alat selesai, pada bab ini akan berisi tentang pengujian sistem pada alat yang dirangkai sesuai dengan perancangan pada bab sebelumnya untuk mengetahui apakah alat berjalan sesuai

yang

direncanakan. Pengujian dilakukan

untuk membandingkan

hasil perancangan teoritis dengan hasil percobaan. Dari hasil pengujian dapat diketahui apakah alat telah bekerja sesuai dengan yang diinginkan pada perancangan alat.

Hal yang terpenting harus diperhatikan dalam membuat sesuatu perancangan yaitu diagram blok yang mencangkup cara kerja dari alat yang dirancang, kemudian karakteristik komponen yang digunakan, keselurahan blok diagram implementasi pada alat billboard (papan iklan) digital menurut usia dengan menggunakan metode jaringan saraf tiruan.

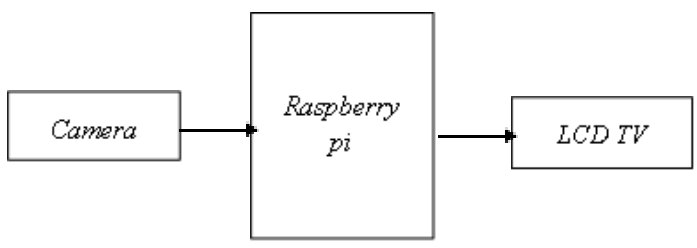

Gambar 2 Blok Diagram

Pada Gambar 2 merupakan blok diagram yang menjelaskan sistem kerja dari alat yang digunakan pada penelitian merupakan mode input masukan pada sistem papan iklan digital. Input tersebut merupakan suatu program yang dibuat untuk menangkap gambar yang nantinya akan diolah dalam raspberry pi yang berfungsi mengolah data dan mengirimkan hasil yang akan ditampilkan ke layar LCD TV.

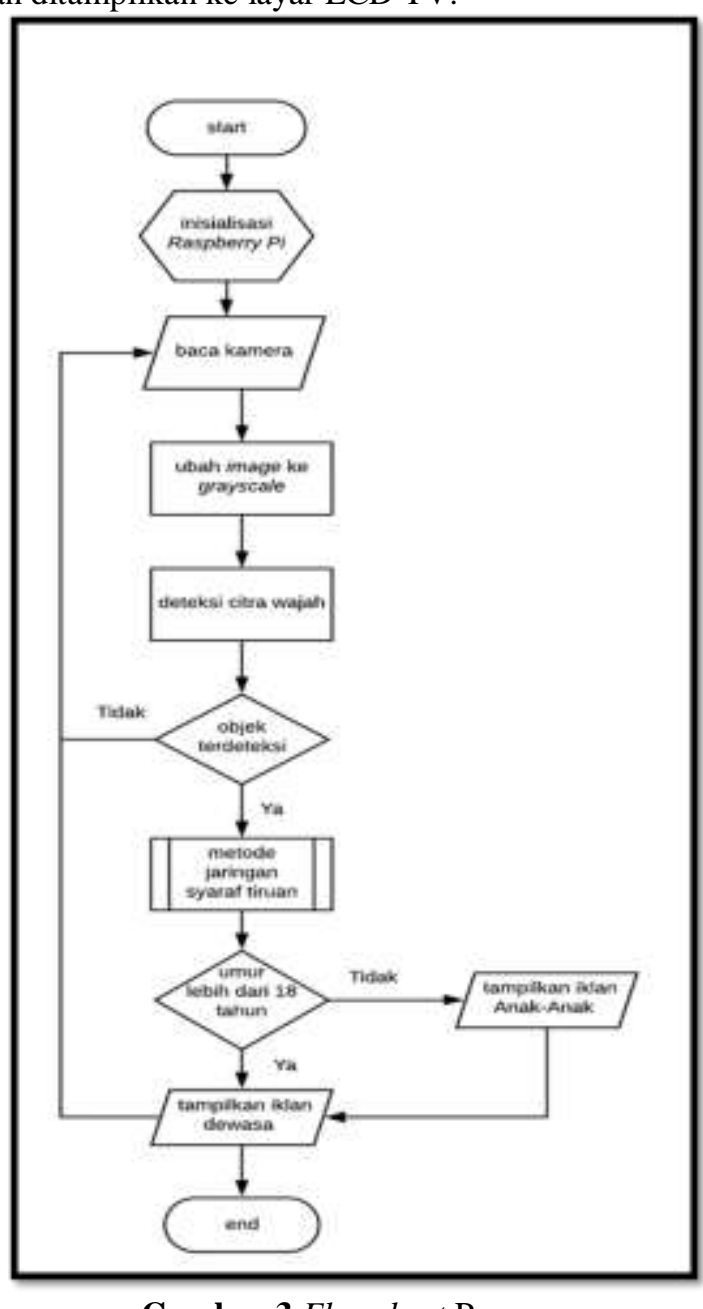

Gambar 3 Flowchart Program

Gambar 3 menunjukkan sistem keseluruhan dimulai dari start program dan inisialisasi port raspberry pi yang digunakan, setelah itu data citra digital dideteksi oleh kamera. Gambar kemudian diubah dari gambar berwarna menjadi hitam putih. Setelah citra input langsung akan di proses untuk penentuan area pendeteksian citra yang telah ditangkap kamera. Deteksi objek akan diproses oleh face detection jika objek wajah tidak terdeteksi maka proses akan kembali ke pembacaan citra oleh kamera. Jika objek wajah terdeteksi maka objek wajah akan diproses ke dalam metode jaringan saraf tiruan untuk menentukan usia objek dari citra wajah. Selanjutnya proses dilanjutkan dengan menampilkan iklan sesuai dengan usia. Jika usia lebih dari 18 tahun maka akan menampilkan iklan dewasa, jika kurang dari 18 tahun maka akan menampilkan iklan anak-anak. Setelah iklan selesai ditampilkan maka proses akan kembali ke pembacaan citra oleh kamera.

Program dibawah menunjukkan bagian kanal utama prediksi usia dari metode jaringan syaraf tiruan yang bertujuan bagaimana sistem dapat menentukan serta mengenali objek berdasarkan usia. 


\section{Sistem Billboard Digital Cerdas Menggunakan Metode Jaringan Syaraf Tiruan dengan Orientasi Pendeteksi Jarak dan Usia}



Gambar 4 Program Prediksi Usia Dari Metode Jaringan Saraf Tiruan

\section{HASIL PEMBAHASAN}

A. Hasil Pengujian Pada Program Citra Digital

Untuk kamera yang digunakan adalah webcam Logitech B525 full HD dengan resolusi maksimal 1920x1080 pixel yang berfungsi sebagai penangkap citra dari objek dengan hasil yang detail dan cerah. Perangkat kamera ini sebagai pendeteksi objek berupa wajah yang akan diproses pada raspberry $\mathrm{pi}$.

Langkah awal dalam melakukan deteksi wajah adalah melakukan training data set agar program dapat menyimpan berbagai klasifikasi yang membentuk skema model wajah, selanjutnya yaitu kamera akan disiapkan untuk mengambil data kamera secara real time. Pada pengujian deteksi wajah yang akan dilakukan menggunakan sampel wajah dan kamera akan mengambil sampel ini menjadi input dari kamera yang akan terdeteksi untuk diproses pada raspberry pi.

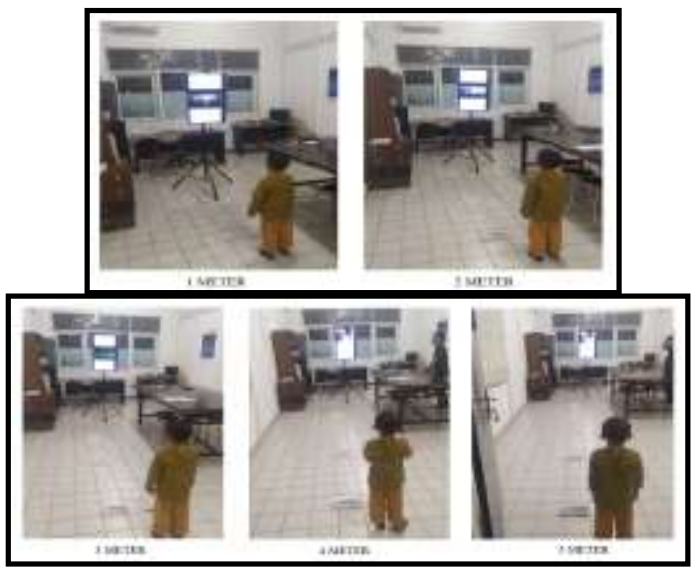

Gambar 4 Tampilan Hasil Deteksi Jarak pada Objek

Dalam kehidupan kita mengenal apa yang dinamakan objek yaitu benda yang dijadikan sasaran untuk diteliti sedangkan untuk gerak menurut ilmu fisika adalah proses perpindahan suatu benda dari suatu kedudukan yang lain. Pada pengujian deteksi wajah yang telah dilakukan menggunkan sampel wajah dengan pengaturan jarak sebagai parameternya dapat dilihat bahwa hasil pada satu meter pertama dan kedua masih menunjukan usia dengan tingkat akurasi yang baik, ketika di meter ke tiga dan ke empat hasil objek masih dapat terdeteksi tetapi usia yang ditampilkan tingkat akurasi yang kurang karena dihasilkan usia yang tidak sesuai dengan objek. Pada jarak lima meter wajah dan usia objek sudah tidak dapat terdeteksi. Hal tersebut dijelaskan pada tabel 1.

Tabel 1. Pengujian Jarak Objek Orang Dewasa dan Anak-anak

\begin{tabular}{|c|c|c|c|c|}
\hline \multirow[b]{2}{*}{ No } & \multirow{2}{*}{$\begin{array}{c}\text { Sampel } \\
\text { Pengujian }\end{array}$} & \multirow{2}{*}{$\begin{array}{c}\text { Jarak } \\
\text { (meter) }\end{array}$} & \multicolumn{2}{|c|}{ Hasil } \\
\hline & & & Terdeteksi & $\begin{array}{c}\text { Tidak } \\
\text { Terdeteksi }\end{array}$ \\
\hline \multirow{5}{*}{1} & \multirow{5}{*}{ Dewasa } & 1 & $\mathrm{Ya}$ & Tidak \\
\hline & & 2 & $\mathrm{Ya}$ & Tidak \\
\hline & & 3 & $\mathrm{Ya}$ & Tidak \\
\hline & & 4 & Tidak & $\mathrm{Ya}$ \\
\hline & & 5 & Tidak & $\mathrm{Ya}$ \\
\hline \multirow{5}{*}{2} & \multirow{5}{*}{ Anak-anak } & 1 & Ya & Tidak \\
\hline & & 2 & Ya & Tidak \\
\hline & & 3 & $\mathrm{Ya}$ & Tidak \\
\hline & & 4 & Tidak & $\mathrm{Ya}$ \\
\hline & & 5 & Tidak & $\mathrm{Ya}$ \\
\hline
\end{tabular}

Hasil pengujian deteksi wajah yang telah dilakukan menggunkan sampel wajah dengan pengaturan jarak sebagai parameternya dan dilakukan oleh beberapa objek didapatkan hasil pada satu meter pertama sampai meter ketiga dengan tingkat akurasi yang baik, ketika di meter ke empat objek masih terbaca oleh kamera tetapi didapatkan hasil kurang maksimal. Pada jarak lima meter wajah dan usia objek sudah tidak dapat terdeteksi oleh kamera

Tabel 2. Hasil Pengujian Objek Jarak ada Deteksi Kamera

\begin{tabular}{|c|c|c|c|c|}
\hline \multirow[b]{2}{*}{ No } & \multirow[b]{2}{*}{ Objek } & \multirow{2}{*}{$\begin{array}{c}\text { Jarak } \\
\text { (meter) }\end{array}$} & \multicolumn{2}{|c|}{ Hasil } \\
\hline & & & Terdeteksi & $\begin{array}{c}\text { Tidak } \\
\text { Terdeteksi }\end{array}$ \\
\hline \multirow{5}{*}{1} & & 1 & Ya & Tidak \\
\hline & & 2 & Ya & Tidak \\
\hline & & 3 & Ya & Tidak \\
\hline & & 4 & Ya & Tidak \\
\hline & $\mathrm{De}$ & 5 & Tidak & $\mathrm{Ya}$ \\
\hline \multirow{5}{*}{2.} & & 1 & $\mathrm{Ya}$ & Tidak \\
\hline & & 2 & Ya & Tidak \\
\hline & & 3 & Ya & Tidak \\
\hline & & 4 & Ya & Tidak \\
\hline & & 5 & Tidak & $\mathrm{Ya}$ \\
\hline \multirow{5}{*}{3.} & & 1 & Ya & Tidak \\
\hline & & 2 & Ya & Tidak \\
\hline & & 3 & Ya & Tidak \\
\hline & & 4 & Ya & Tidak \\
\hline & Anak & 5 & Tidak & Ya \\
\hline \multirow{5}{*}{4.} & & 1 & $\mathrm{Ya}$ & Tidak \\
\hline & & 2 & Ya & Tidak \\
\hline & & 3 & Ya & Tidak \\
\hline & & 4 & Ya & Tidak \\
\hline & Anak-anak 3 & 5 & Tidak & Ya \\
\hline
\end{tabular}

Untuk pengujian akurasi dengan hasil pendeteksian yang didapatkan berdasarkan data sebanyak 20 kali hasil capture/tangkapan gambar, 


\section{Sistem Billboard Digital Cerdas Menggunakan Metode Jaringan Syaraf Tiruan dengan Orientasi Pendeteksi Jarak dan Usia}

dilakukan pengujian akurasi dengan menggunakan persamaan sebagai berikut:

$$
\text { Akurasi }=\frac{\text { jumlah data benar }}{\text { keseluruhan data }} \times 100 \text { \$S }
$$

Berdasarkan persamaan akurasi yang digunakan maka didapatkan jumlah data benar sebanyak 16 hasil capture yang menunjukkan hasil tangkapan gambar dengan hasil pendeteksian yang dinyatakan benar, sedangkan untuk hasil capture atau tangkapan jumlah data tidak terdeteksi atau error sebanyak 4 kali. Berdasarkan data tersebut dihitung dengan perhitungan matematis maka didapatkan data akurasi dari pengujian ini dengan akurasi rata-rata yang didapatkan adalah $80 \%$. Hasil akurasi ini merupakan hasil akurasi deteksi wajah yang ditangkap oleh kamera.

\section{KESIMPULAN}

Berdasrakan hasil yang didapat dalam penelitian yang dilakukan, maka diperoleh kesimpulan sebagai berikut:

Penerapan metode jaringan saraf tiruan cocok digunakan karena memiliki tingkat akurasi yang baik jika dilihat dari performa dengan nilai-nilai maksimum pembacaan gambar yang dibandingkan dengan kondisi real, sehingga pengaturan tampilan dalam sistem periklanan diperlukan filter dalam penyampaian proses penampilan iklan dengan memikirkan dampak negatif yang ditimbulkan dalam proses penyampaian iklan maka diperlukan filter untuk menyaring data atau tampilan iklan. Dalam pencapaian penelitian ini iklan dapat di implementasikan sebagai pencapaian proses tampilan dengan memikirkan dampak negatif yang ditimbulkan. Dalam proses penyampaian iklan maka diperlukan filter untuk menyaring data atau tampilan iklan dengan metode jaringan saraf tiruan.

Untuk pengujian alatnya menggunakan parameter jarak berdasarkan objek yang terdekteksi dengan dua katagori yaitu dewasa dan anak-anak. Untuk hasil pengujian menggunakan 4 objek orang dengan jarak 1 meter sampai dengan 5 meter per objek didapatkan hasil terdeteksi masing-masing orang dewasa dan anak kecil dijarak 1 meter sampai 3 meter dijarak 4 meter sampai 5 meter tidak terdeteksi dengan akurasi $80 \%$.

\section{DAFTAR PUSTAKA}

[1] S. C. Satapathy, V. Bhateja, And A. Joshi, "Proceedings Of The International Conference On Data Engineering And Communication Technology: Icdect 2016. Volume 2," Int. J. Eng. Res. Technol., 2020.

[2] S. K. Sugiarto, I. Mujahidin, And A. B. Setiawan, "2, 5 Ghz Antena Mikrostrip Polarisasi Circular Model Patch Yin Yang Untuk Wireless Sensor," Jeecae (Journal Electr. Electron. Control. Automot. Eng., Vol. 4, No. 2, Pp. 297-300, 2019.

[3] I. Mujahidin, "Radar Introduction Class," Http://Antenapropagasi.Blogspot.Com/2018/11/Radar-
Introduction-Class.Html, No. 2. 2018.

[4] I. Mujahidin, "Parameter Antena," Http://Antenapropagasi.Blogspot.Com/2016/02/Param eter-Antena.Html. 2018.

[5] I. Mujahidin, "Smart Transducers," Http://Antenapropagasi.Blogspot.Com/2018/11/SmartTransducers.Html. 2018.

[6] I. Mujahidin, D. A. Prasetya, Nachrowie, S. A. Sena, And P. S. Arinda, "Performance Tuning Of Spade Card Antenna Using Mean Average Loss Of Backpropagation Neural Network," Int. J. Adv. Comput. Sci. Appl., 2020.

[7] R. Yuwono, I. Mujahidin, A. Mustofa, And Aisah, "Rectifier Using Ufo Microstrip Antenna As Electromagnetic Energy Harvester," Adv. Sci. Lett., 2015, Doi: 10.1166/Asl.2015.6574.

[8] D. A. Ayubi, D. A. Prasetya, And I. Mujahidin, "Pendeteksi Wajah Secara Real Time Pada 2 Degree Of Freedom (Dof) Kepala Robot Menggunakan Deep Integral Image Cascade," Cyclotr. J. Tek. Elektro, Vol. 3, No. 1, 2020.

[9] I. Mujahidin, "Directional Couplers," Http://Antenapropagasi.Blogspot.Com/2018/11/Directi onal-Couplers.Html, No. 1. 2018.

[10] I. Mujahidin, "Vswr (Voltage Standing Wave Ratio) Dan Return Loss," Http://Antenapropagasi.Blogspot.Com/2016/02/VswrVoltage-Standing-Wave-Ratio-Dan.Html. 2018.

[11] D. A. Prasetya, A. Sanusi, G. Chandrarin, E. Roikhah, I. Mujahidin, And R. Arifuddin, "Small And Medium Enterprises Problem And Potential Solutions For Waste Management," J. Southwest Jiaotong Univ., Vol. 54, No. 6, 2019.

[12] M. Wibowo, S. Suprayogi, And I. Mujahidin, "Rancang Bangun Sistem Pengamanan Rak Senjata M16 Menggunakan Rfid Dan Fingerprint," Jasiek (Jurnal Apl. Sains, Informasi, Elektron. Dan Komputer), Vol. 1, No. 2, Pp. 134-142, 2019.

[13] I. Mujahidin And P. S. Arinda, "Antena Compact Double Square Marge 2, 6ghz Dengan Output Perbedaan Fase 90 Derajat Untuk Aplikasi Lte," Jeecae (Journal Electr. Electron. Control. Automot. Eng., Vol. 4, No. 2, Pp. 273-278, 2019.

[14] E. Endrayana, D. H. S. Wahyuni, N. Nachrowie, And I. Mujahidin, "Variasi Ground Plane Antena Collinear Pada Pemancar Telivisi Analog Dengan Frekuensi Uhf 442 Mhz," Jasiek (Jurnal Apl. Sains, Informasi, Elektron. Dan Komputer), Vol. 1, No. 2, Pp. 149-156, 2019.

[15] I. Mujahidin, "Directional 1900 Mhz Square Patch Ring Slot Microstrip Antenna For Wcdma," Jeemecs (Journal Electr. Eng. Mechatron. Comput. Sci., 2019, Doi: 10.26905/Jeemecs.V1i2.2626.

[16] I. Mujahidin And B. F. Hidayatulail, "2.4 Ghz Square Ring Patch With Ring Slot Antenna For Self Injection Locked Radar," Jeemecs (Journal Electr. Eng. Mechatron. Comput. Sci., Vol. 2, No. 2, 2019.

[17] I. Mujahidin, "Pll (Phase Locked Loop)," Http://Antenapropagasi.Blogspot.Com/2018/11/PllPhase-Locked-Loop.Html. 2018.

[18] D. F. C. Kusuma, D. A. Prasetya, F. Kholid, And I. Mujahidin, "Evaluasi Database Senjata Untuk Sistem Keamanan Menggunakan Fuzzy Logic," Jasiek (Jurnal Apl. Sains, Informasi, Elektron. Dan Komputer), Vol. 1, No. 2, Pp. 111-116, 2019.

[19] I. Mujahidin, "Langkah Desain Antena," Http://Antenapropagasi.Blogspot.Com/2016/02/Langk 


\section{Sistem Billboard Digital Cerdas Menggunakan Metode Jaringan Syaraf Tiruan dengan Orientasi Pendeteksi Jarak dan Usia}

ah-Desain-Antena.Html. 2018.

[20] A. E. Pambudi, L. Maajid, J. Rohman, And I. Mujahidin, "Aplikasi Penggunaan Joystick Sebagai Pengendalian Remote Control Weapon Station (Rcws) Senjata Mesin Ringan (Smr)," Jasiek (Jurnal Apl. Sains, Informasi, Elektron. Dan Komputer), Vol. 1, No. 2, Pp. 98-105, 2019.

[21] B. F. Hidayatulail And I. Mujahidin, "Potential Of 77, $78 \mathrm{Mw}$ Red Diode Laser For Photodynamic," Jeemecs (Journal Electr. Eng. Mechatron. Comput. Sci., Vol. 2, No. 2, 2019.

[22] I. Mujahidin, S. H. Pramono, And A. Muslim, "5.5 Ghz Directional Antenna With 90 Degree Phase Difference Output," 2018, Doi: 10.1109/Eeccis.2018.8692872.

[23] T. A. S, A. Rabi', D. Minggu, And I. Mujahidin, "Frequency Hopping Video Real Time Untuk Pengamanan Data Pengintaian Operasi Inteligence Tni," Jasiek (Jurnal Apl. Sains, Informasi, Elektron. Dan Komputer), 2019, Doi: 10.26905/Jasiek.V1i1.3146.

[24] J. Lasmono, A. P. Sari, E. Kuncoro, And I. Mujahidin, "Optimasi Kerja Peluncur Roket Pada Robot Roda Rantai Untuk Menentukan Ketepatan Sudut Tembak," Jasiek (Jurnal Apl. Sains, Informasi, Elektron. Dan Komputer), 2019, Doi: 10.26905/Jasiek.V1i1.3149.

[25] D. A. Prasetya, A. Sanusi, G. Chandrarin, E. Roikhah, I. Mujahidin, And R. Arifuddin, "Community Culture Improvisation Regarding Waste Management Systems And Per Capita Income Increase," J. Southwest Jiaotong Univ., Vol. 54, No. 6, 2019.

[26] I. Mujahidin, "Tutorial Memulai CST- Project Baru Untuk Antena Mikrostrip," Http://Antenapropagasi.Blogspot.Com/2016/02/Tutori al-Memulai-Cst-Project-Baru-Untuk.Html. 2018.

[27] I. Mujahidin, "Elemen Antena," Http://Antenapropagasi.Blogspot.Com/2016/02/Eleme n-Entena.Html. 2018.

[28] R. Yuwono And I. Mujahidin, "Rectifier Using Uwb Microstrip Antenna As Electromagnetic Energy Harvester For Gsm, Cctv And Wi-Fi Transmitter," J. Commun., 2019, Doi: 10.12720/Jcm.14.11.1098-1103.

[29] I. Mujahidin, R. Yuwono, And A. Mustofa, "Rancang Bangun Rectifier Antenna Mikrostrip UFO Pada Frekuensi Ultra Wideband (Uwb) Sebagai Pemanen Energi Elektromagnetik," J. Mhs. Teub, Vol. 3, No. 2, 2015.

[30] I. Mujahidin, D. A. Prasetya, A. B. Setywan, And P. S. Arinda, "Circular Polarization 5.5 Ghz Double Square Margin Antenna In The Metal Framed Smartphone For Sil Wireless Sensor," In 2019 International Seminar On Intelligent Technology And Its Applications (Isitia), 2019, Pp. 1-6.

[31] M. T. Prakarsa, D. Wahyuni, N. Rachman, And I. Mujahidin, "Optimasi Sistem Komunikasi Dari HT Dengan Hp Dalam Pelaksanaan Tugas Operasi Tni Ad Menggunakan Metode Dtmf," Jasiek (Jurnal Apl. Sains, Informasi, Elektron. Dan Komputer), 2019, Doi: 10.26905/Jasiek.V1i1.3150.

[32] I. Mujahidin, "Desain Matematis Antena Mikrostrip," Http://Antenapropagasi.Blogspot.Com/2016/02/Desai n-Matematis-Antena-Mikrostrip_17.Html. 2018.

[33] I. V. Robbyvalentino, N. Nachrowie, D. W, And Mujahidin, "Rancang Bangun Sistem Penilaian Kesegaran Jasmani A Di Jajaran Tni-Ad Berbasis Rfid," Jasiek (Jurnal Apl. Sains, Informasi, Elektron. Dan Komputer), Vol. 2, No. 1, Pp. 98-106, 2020.
[34] E. De La Rosa And W. Yu, "Data-Driven Fuzzy Modeling Using Restricted Boltzmann Machines And Probability Theory," Ieee Trans. Syst. Man, Cybern. Syst., 2020, Doi: 10.1109/Tsmc.2018.2812156. 